\title{
Learning acidity in the context of molecular gastronomy through argumentation - Making of a blueberry trio
}

\author{
Linnea Töyrylä \\ Unit of Chemistry Teacher Education, Department of Chemistry, University of Helsinki, Finland • \\ linnea.toyryla@gmail.com

\section{Maija Aksela} \\ Unit of Chemistry Teacher Education, Department of Chemistry, University of Helsinki, Finland • \\ maija.aksela@helsinki.fi
}

\author{
Anu Hopia \\ Functional Foods Forum, University of Turku, Finland • anu.hopia@gmail.com

\section{Erik Fooladi} \\ Volda University College \& Norwegian Centre for Science Education, Norway • ef@hivolda.no
}

\begin{abstract}
The aim of the new material is to support students' learning of chemistry: acidity and pHindicators, especially anthocyans, and their argumentation. The material presented here was tested with both teachers and students. This material can be used with elementary school students and high school students. It is also an example on how to bring molecular gastronomy and food chemistry into the chemistry teaching.
\end{abstract}

\section{Introduction}

The goal of this material is to support students' learning of chemistry: acidity and $\mathrm{pH}$ indicators. Acidity as a phenomenon is mentioned in the Finnish national curriculum (Finnish National Board of Education, 2004) as one of the crucial contents under the subject air and water. It is usually taught in either the eighth or ninth grade. The material can also be used with younger or older students, but then the amount of theory and the required quality of argumentation must be adjusted.

The material is meant to be used during a 75 minute lesson. This time should be sufficient for a short presentation about argumentation, the experiment itself, the argumentation phase and a short time for discussing the results with the students. The ending discussion is a vital part of the lesson as it is important that all students have the correct information to avoid letting them form false deductions about the results.

The material was planned to be used after teaching the basics of acids and bases. If the students do not have knowledge about the theory or terms, it is harder or even impossible to make good arguments. The material can also be used in the beginning of teaching acids and bases, but then the argumentation part should be left out or made considerably easier by providing extra information or such for the students. 


\section{Experimental part}

The following experiment is recommended to be executed mainly at a home economy class. It can also be done in a regular classroom where running water is available. The materials needed for the experiment are:

Materials for four (4) students:

- 1 egg white

- $0,5 \mathrm{dl}$ sugar

- 2 dl blueberries (frozen)

- 250 g quark

- $1 \mathrm{dl}$ whipped cream

- $15 \mathrm{ml}$ lemon juice
- two bowls

- two whisks

- cups for the portions (ideally seethrough)

- spoons

\section{The recipe: Blueberry Trio (for four)}

A three-layered blueberry dessert.

Ingredients:

Foam (the top layer)

- 1 egg white

- 1 tbsp sugar

- $0,5 \mathrm{dl}$ blueberries (whole, frozen)

The bottom layer

- $0,5 \mathrm{dl}$ blueberries (whole, frozen)
Quark (the middle layer)

- 250 g quark

- $1 \mathrm{dl}$ whipped cream

- $0,5 \mathrm{dl}$ sugar

- $15 \mathrm{ml}$ lemon juice

- $1 \mathrm{dl}$ blueberries (whole, frozen)

Preparations:

1. Separate the egg white and whip it into a firm foam. Add the sugar and blueberries. Mix carefully.

2. Whip the cream into a loose foam and add the quark. Mix well. Add the sugar, lemon juice and blueberries. Mix.

3. Prepare the portions: put some blueberries in the glass so that the bottom is covered. Set The quark as the middle layer and top the portion with the egg white foam.

The resulting portion should look something like this:

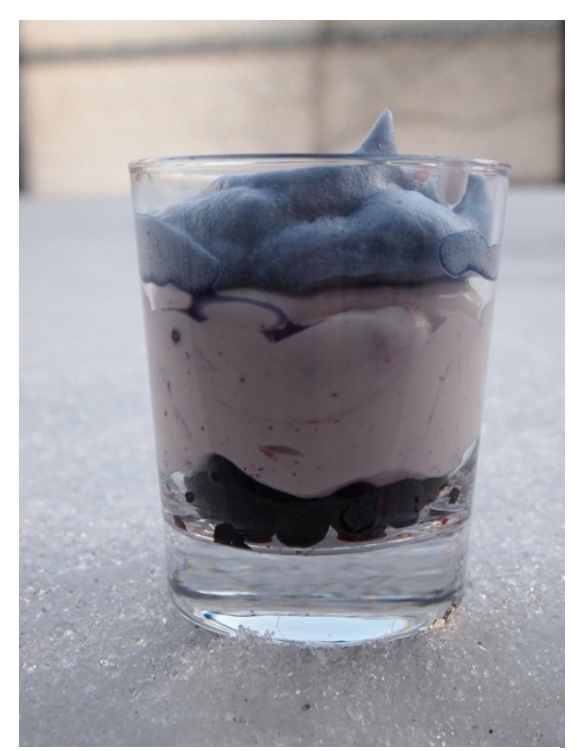

Figure 1. The blueberry trio. 


\section{Pedagogical advices}

One aim of the experiment is to learn acidity through argumentation. That's why teaching of the topic begins with a short presentation about argumentation. The students are presented with the idea of argumentation and one short example of an argumentative discussion. If possible it would also be good to have a short discussion of argumentation and let the students make deductions on what makes an argument good. Possible answers could be for example referring to an authority, the result of an observation or an experiment. After the discussion the students are presented with the experiment: making of a blueberry trio. The students are presented with the recipe and it might be best to go through it together so as to avoid mistakes.

After making the dessert the students are presented with three claims. The students should prepare an argument about them and deduce whether they are true or false and why. Textbooks or notebooks can be used as sources of information and the students should be allowed to test the $\mathrm{pH}$ of the ingredients with indicator paper. The claims are as follows:

1. In a basic environment the blueberry juice appears red.

2. Blueberry juice makes the quark acidic.

3. Lemon juice is more acidic than quark.

If argumentation is hard for the students it is possible to offer them these sentences to help with forming arguments:

- I think this is false because...

- My data/ warrant for this is...

- Some might argue that...

- This is how I would present my argument to the person being of different opinion...

The answers for the claims are:

1. The claim is false. In basic conditions the blueberry juice turns blue. This can be tested by measuring the $\mathrm{pH}$ of the egg whites (basic) and the quark (slightly acidic).

2. True and false. It can be argued that it is actually the lactic acid that makes the quark acidic. But then again the blueberry juice itself and also the lemon juice are acidic so they make the quark more acidic.

3. True. This can be tested by measuring the $\mathrm{pHs}$ of the quark and lemon juice. It is also possible to argue about this by taste (lemon juice tastes more acidic) or referring to the textbooks. In many text books it is mentioned that the $\mathrm{pH}$ of lemon is approximately 2 and the $\mathrm{pH}$ of milk is approximately 6 .

The argumentation could commence while or before consuming the desserts. After students have been given sufficient time for argumentation the claims should be discussed. When using true-or-false-statements in teaching it is important to go through the statements together or with each group so that no one ends up with false information. 
To wrap the lesson up one can have a short presentation about anthocyans and blueberries as indicators (see a text later on). A very easy-to-understand example is to think of the color of a person's skin after handling blueberries: because skin is slightly acidic the blueberry stains appear red or purple but when you wash your hands with basic soap the stains turn blue.

When the material was tested it was used just after the teaching of the basics of acidbase chemistry. During the previous lessons the students had also practiced using indicator paper. If the students are familiar with basic information concerning acids and bases and know how to measure $\mathrm{pH}$ this material is much easier to carry out. It can also be used as a fun activity at the end of the course or to revise the acid-base chemistry that has been learned.

An optimal group size for making this dessert is three or four students. In this case there should be a sufficient amount of work for each student. When whipping the cream and egg whites for the dessert it is good to use manual whisks. That will both reduce the sound level of the class room compared to using electronic whisks and gives the students something to do. In some cases it might even make the student calmer. The basic manual whisks are also cheaper to buy if the utensils have to be bought.

The amount of theory should be adjusted according to the age of the students and their knowledge level. This material can be used with elementary school students and high school students. Also the level of the argumentation should be adjusted. Older students should be required to make proper arguments to back the claims.

It should also be noted that the material presented here is only one way to promote argumentation in the chemistry class room. Proper argumentation is not learned in a blink of an eye but it needs practice. A teacher can help a student with the argumentation by asking extra questions or trying to refute the student's argument making it necessary for the student to defend their own argument.

\section{Theory of $\mathrm{pH}$ indicators}

$\mathrm{pH}$ indicators are substances that change their color according to $\mathrm{pH}$. There are also many $\mathrm{pH}$ indicators in nature and one group of these is flavonoids. Anthocyans are a subgroup to flavonoids. They are water-soluble pigments and occur in flowers, fruits and berries. They are either of violet, blue or red color. (Swain, 1976)

All anthocyans are built around the same basic structure, the flavylium-ion. The flavylium-ions have seven possible subgroups that are either hydrogens, hydroxides or metox-groups. By changing the groups we get a variety of different anthocyans.

Anthocyans work as $\mathrm{pH}$ indicators because of their ability to reflect light in a different way according to the surrounding $\mathrm{pH}$. In acidic conditions anthocyans appear red and in 
neutral conditions they appear in various shades of violet. In basic conditions anthocyans appear blue and eventually lose their color altogether. (Chigurupati et al, 2002)

Chemically anthocyans can be divided into two groups: anthocyanidins and anthocyanins. In anthocyanins there is a sugar molecule attached to one or two different positions of the flavylium-ion. The anthocyanidins have no sugar molecules attached to them and are called aglycones.

The most common anthocyans in blueberries (Vaccinium myrtillus) are delphinidin and cyanidin. The other three are malvidin, peonidin and petunidin. Altogether there are 15 different anthocyaninglycosides found in blueberries. Each of them is a compound made out of one of the forementioned anthocyans and a sugar, which can be either glucose, galactose or arabinose. (Kalt et al, 1999)

\section{Theory of argumentation}

Argumentation is a vital part of natural sciences, because without argumentation new information can't be formed. Students' skills in argumentation and teaching argumentation have been investigated around the world and it has been noted that both students and teachers have lacking skills in argumentation.

Argumentation and argument are two different terms that need to be set apart. An argument means the actual claim and the relevant data and warrants that support it. Argumentation means the actual conversation, where these arguments are used. (mm. Osborne et al., 2004) Also, in this context we are specifically looking into scientific arguments. For scientific arguments it is typical for them to have certain simplifications and that data is often received from experiments or observations (Newton, 1999).

When testing the material Toulmin's argumentation pattern (Toulmin, 1958) and Erduran et al.'s (2004) application of it were used as a basis for evaluating argumentation. In Toulmin's argumentation pattern the arguer needs data and warrants in addition to the claim. It is also possible to use backings to support the warrant and add qualifiers and reservations to the claim.

Erduran et al.'s application of Toulmin's argumentation pattern offers an analytical framework for evaluating argumentation. Argumentation is divided into five levels according to the quality of argumentation. In level 1 the argumentation consists of only claims and counter-claims. Level 5 is described as extended argumentation that has more than one rebuttals. Levels 2- 4 have different amounts of warrants and backings with no or some rebuttal. (Erduran et al., 2004) Rebuttals are used when trying to contradict someone else's claims. 


\section{References}

Chigurupati, N., Saiki, L., Gayser, C., \& Dash, A.K. (2002). Evaluation of red cabbage dye as a potential natural color for pharmaceutical use. International J ournal of Pharmaceutics, 241(2), 293- 299.

Erduran, S., Simon, S., \&Osborne, J . (2004). TAPping into Argumentation: Developments in the Application of Toulmin's Argument Pattern for Studying Science Discourse. Science Education, 88(6), 915-933.

Finnish National Board of Education. (2004). National core curriculum for comprehensive school 2004. Helsinki: Finnish National Board of Education.

Kalt, W., McDonald, J .E., Ricker, R.D., \&Lu, X. (1999). Anthocyanin content and profile within and among blueberry species. Canadian J ournal of Plant Science, 79, 617- 623.

Newton, P. (1999). The place of argumentation in the pedagogy of school science. International J ournal of Science Education, 21(5), 553- 576.

Osborne, J ., Erduran, S., \& Simon, S. (2004). Enhancing the quality of argumentation in school science. J ournal of Research in Science Teaching, 41(10), 994- 1020.

Swain, T. (1976). Nature and Properties of Flavonoids. In T.W. Goodwin (Ed.), Chemistry and Biochemistry of Plant Pigments (pp. 425-461). London: Academic Press Inc.

Toulmin, S. (1958). The Uses of Argument. Cambridge: University Printing House. 